\title{
CORRESPONDENCE
}

Bladder cancer as a prescribed

industrial disease

C A Veys, MD; D Leon, BA . . . . . . . . . . 1053

Systematic review of the

benzodiazepines

E S Snell, FRCP . . . . . . . . . . . . . 1053

\section{Kidney biopsy}

J R T Gabriel, FRCP; M C Bateson, MD;

R G Hughes, frCs. . . . . . . . . . . 1054
Vitamin D supplements in Asian women

J G Bissenden, MRCP; O G Brooke, MD, and I R F Brown, MRCPATH. . . . . . . . . . 1054

Polypharmacy in rheumatic diseases

R C Hamdy, MRCP, and others. . . . . . . . 1054

Trimethoprim resistance in Finland H E Busk, MD, and B Korner, MD . . . . . . 1054

Examination of abortuses

A J Barson, MD . . . . . . . . . . . . . . . . 1055
Mebendazole and hydatid disease

A L Macnair, MB . . . . . . . . . . . . . 1055

Lumbar puncture

C E Blogg, FFARCS; C G Clough, MRCP, and

J M S Pearce, FRCP; J K Hasler, FFARCS. . 1055

Awareness in general anaesthesia

R H Whitaker, FRCS; B Williams, FRCOG;

I F Russell, FFARCS; A R Ryan, FFARCs; J

B Skinner, fFARCs. . . . . . . . . . . . . 1056

\section{Bladder cancer as a prescribed industrial disease}

SIR,-The paper by Sheena $M$ Somerville and others (23 February, p 540) is a timely reminder to clinicians to probe more often into the retrospective life-long occupational history of their patients who present with a neoplasm of the urinary tract. In reply to their question in their follow-up letter (22 March, $p$ 867) asking how the present state of affairs might be improved, I can offer one suggestion-albeit emanating from the other end of the spectrum.

Stoke-on-Trent has had since 1965 a coroner's notification scheme for all patients certified as dying from bladder cancer, whether this was directly related to the cause of death or not. This has been fully described elsewhere. ${ }^{1}$ One advantage of the scheme is that it increases doctors' awareness of the relationship between disease and the working environment. Since 1965 I have attended many inquests in order to establish whether this relationship was, in fact, causal; and in 17 instances it was. One rodent controller was exposed to the rodenticide antu containing residual beta-naphthylamine; three firelighter makers to carcinogenic aromatic amines emanating from the hot creosote oil over which they leaned, breathing fumes as they dipped the wooden faggots; and 13 ex-rubber workers were exposed to similar aromatic amines, which contaminated certain antioxidants used in rubber processing up to the end of 1949, when they were promptly withdrawn. All 17 cases were accorded the right to apply for industrial death benefit, and were encouraged to do so.

The Stoke-on-Trent firelighter makers may feel aggrieved at being left out of Somerville and Davies's otherwise comprehensive list; but as doctors we might feel equally concerned at our failure to recognise and help those who gave up their health and even life in the normal pursuance of their job.

Charles Veys

Industrial and Community Health Research Unit, North Staffs Medical Institute,

Stoke-on-Trent ST4 7NY

1 Veys, CA. Br f Ind Med 1974;31 :65-71.

SIR,-We support the view expressed by Sheena Somerville and her colleagues in their letter (22 March, p 876) that there is serious underclaiming of benefits for prescribed disease No 39-papilloma of the bladder. St Peter's Hospitals have run a claims service for patients with bladder cancer since 1977 We too have found that about one in 20 patients interviewed is eligible for benefit. This is well in excess of the proportion that would be expected on the basis of the national experience.

In Britain over the period 1967-8 to $1971-2$ there was a total of 127 new awards of injury or disablement benefit made in cases of occupational bladder cancer. ${ }^{1}$ Virtually all the awards were to men. In the corresponding five-year period 1967-71 an average of 5500 new cases of bladder cancer in men was registered annually in Britain. One would therefore expect an average of less than one man in 200 with bladder cancer to be eligible for benefit. The considerable difference between this proportion derived, albeit rather crudely, from national aggregate figures and the proportion of St Peter's and Royal

\section{Systematic review of the benzodiazepines}

SIR,-In the wake of alarmist and exaggerated statements on the benzodiazepines in the media and in Parliament a publication of recommendations by the Committee on the Review of Medicines (29 March, p 910) should be welcomed by doctors seeking expert and responsible guidance. However, we fear that in several respects the official response is unsatisfactory and we wish to draw attention to these in your columns.

The format of the statement in the style of data sheets will be confusing. Statutory data sheets already exist on these products and are contained in the Association of the British Pharmaceutical Industry Compendium. These are the official data sheets to guide prescribing by the profession and promotion by the industry. The Medicines Act 1968 requires data sheets to be consistent with product licences but the latter cannot be changed other than through the licensing authority, which acts on recommendations from, among others, the Committee on the Review of Medicines. Manufacturers have the right of appeal against decisions of the licensing authority and
Marsden cases found eligible for benefit is an indication of the serious extent of underclaiming. Some of this difference may be due to the cases seen at our two hospitals not being completely representative of cases elsewhere. It is unlikely, however, that this could account for much of the discrepancy.

To improve this situation the Institute of Urology, in conjunction with others, is developing a questionnaire to assist clinicians in the crucial step of initially identifying those people most likely to be eligible for benefit. To complement this screening process, carried out at a local level, there is also a need to establish further specialist services to deal with and give expert advice on individual claims. These would perhaps best be organised on a regional basis.

David Leon

Community and Environmental Studies Unit, St Peter's Hospital, London W $\mathrm{C} 2$

${ }^{1}$ Hansard, House of Commons, 31 Januarv 1978, col III.

this association deplores the publication of recommendations by the Committee on the Review of Medicines before the manufacturers have had an opportunity to exercise this right. It would be much more reasonable if any issues between manufacturers and the licensing authority could be settled and any amendments to licences and data sheets completed before statements from either party are published.

It would have been less confusing to have published the recommendations in general terms-as in the commentary by the Committee on the Review of Medicines. By itself this would have met the situation despite some of the details which are open to question. Furthermore the "Guidelines for data sheets" were drawn up without the normal consultations to be expected and were finalised without full examination of the available evidence from manufacturers. Companies have an unrivalled data source on their own products, accumulated both nationally and internationally. Failure to take such information fully into account can easily lead to imperfect decisions. 